\title{
Comparison of Gaussian Plume Model and Lagrangian Particle Model for the Application of Coastal Air Quality Modelling
}

\author{
Rajib Pokhrel ${ }^{1,2}$, Heekwan Lee ${ }^{2, *}$ \\ ${ }^{1}$ School of Engineering, Faculty of Science and Technology, Pokhara University, Pokhara, Nepal \\ ${ }^{2}$ School of Urban and Environmental Engineering, College of Urban Science, Incheon National University, Incheon, Republic of Korea
}

Email address:

rajibp@pu.edu.np (R. Pokhrel), airgroup@inu.ac.kr (H. Lee)

${ }^{*}$ Corresponding author

\section{To cite this article:}

Rajib Pokhrel, Heekwan Lee. Comparison of Gaussian Plume Model and Lagrangian Particle Model for the Application of Coastal Air Quality modelling. American Journal of Environmental and Resource Economics. Vol. 4, No. 4, 2019, pp. 152-158.

doi: 10.11648/j.ajere.20190404.16

Received: October 11, 2019; Accepted: October 31, 2019; Published: December 4, 2019

\begin{abstract}
Incheon is one of the biggest cities located in coastal region where small to big size industries, Incheon sea port, Incheon airport, etc are in operation. The air pollution dispersion from those sources has been major concerns for Incheon coastal area where air emission, dispersion and deposition have been studied using different approaches of monitoring and modeling. Essential meteorological data were acquired by field monitoring and from the published data. GTOPO30 (global digital elevation model with a horizontal grid spacing of 30") was used as terrain data for AERMOD and USGS 30" resolution terrain data was used in $\mathrm{A} 2 \mathrm{C}$ flow/A2C t\&d model. Steady state Gaussian plume dispersion based model, i.e. AERMOD, and Lagrangian puff dispersion based model, i.e. A2Cflow/A2Ct\&d models, were accomplished by introducing the local meteorological and geographical information to test the performance of models around the unsteady air flow area. AERMOD simulation results showed that the pollutants from the source are transported and dispersed around the sources similar to the average wind flow direction. There was no significant difference in pollutants dispersion regardless of land breeze or sea breeze conditions. On the other hand, the results from Lagrangian puff model showed that the puffs transport, and dispersed around the coast area followed the sea/land breeze pattern. The comparative analysis of pollutants deposition estimated by steady state Gaussian plume model and Lagrangian puff model showed that the Gaussian plume model underestimate the pollution dispersion quantity at the onshore site during day time and overestimate during late night to early morning. Hence the Lagrangian based model is recommended for estimating pollutants dispersion and deposition around the unsteady air flow region.
\end{abstract}

Keywords: Air Dispersion Modeling, Gaussian Model, Lagrangian Model, Sea/Land Breeze, Coastal Region

\section{Introduction}

With the advent of industrial revolution and later advent of automobiles, the air quality of most large urban and industrial areas took a nosedive with the rise of airborne particles, black shoots, smog, etc hence the air pollution became a serious problem for large cities and commercial centers at early stage. The World Health Organization (WHO) announced that every year approximately 2.7 million deaths might be attributed by air pollution. Over the past decades, long-term exposure of humans to non-lethal air pollutants and the effects of air pollutants on global and regional atmospheric cycles were studied intensively [1].

Urban air pollution in the form of urban plume is transported by atmospheric wind to rural pristine and wilderness areas far away from its source region. In addition, many rural and agricultural sources as well as natural sources located within and outside the region also contribute to the regional air pollution [2]. The pollutant transport, dispersion and deposition characteristics directly and indirectly depend on the pollutant species, surface topography, local and regional meteorology, etc. [2-3]. 
Mostly air pollutants generated near the coastal line are transported to landward during the daytime along with the sea breeze and seaward during the night time along with the land breeze $[2,4]$. The wind flows over the hilly or mountain terrain transport air pollutants to higher altitude and lower level at the plain area but the horizontal penetration length at the plain area is longer than the one in the mountainous area [5-7]. For studying the air pollution transport, dispersion, deposition mechanism, implementing efficient control measures and strategies, various urban air quality models have been developed.

McPherson (1970) was the first to report about the calculations of the sea breeze and it was followed by Peilke [8], Yamada et al. [9-12] and Kim et al. [5] to present scientists. Recently numerous techniques for complex mesoscale modeling have been developed and practiced for atmospheric modeling [13-14]. Although number of models have been developed and implemented for air dispersion study, common theories are steady state Gaussian plume model and Lagrangian puff dispersion model. Gaussian model use the single formula which responses quickly for computing the dispersion amount and it is frequently applied in decision support software [20]. AERMOD, which has been widely used for the prediction of transport and dispersion of airborne materials from a point source over homogenous boundaries, was designed by scientists of United States Environmental Protection Agency (U.S. EPA) in 1991 and the governing equation of AERMOD is steady state Gaussian plume model [15]. AERMOD has been highly popular and validated in case of environmental impact assessment, however the AERMOD has its own limitation such as it may underestimate the air pollution concentration at onshore during sea breeze period and overestimate during the land breeze period.

On the other hand, Lagrangian models are free from numerical diffusivity and maintain mass conservation. Lagrangian models have been used extensively for prediction of transport and diffusion of air borne materials from a point source over both homogenous and inhomogeneous boundaries. Trajectories of particles are computed by using mean and turbulence velocities and the concept of random walk. The Higher Order Turbulence model for Atmospheric Circulation - Random Puff Transport and Diffusion (HOTMAC-RAPTAD) modeling system (Yamada and Bunker, 1988) has been applied successfully to simulate wind, turbulence, and distributions of pollutant concentration over complex terrain where conventional methods had failed [9]. HOTMAC is a three-dimensional meso-scale model, which is based on a set of second-order turbulence-closure equations. RAPTAD is a three-dimensional Lagrangian puff model, which is based on a random displacement method that the mean and turbulence components of winds are provided by HOTMAC. Successful simulations of concentration distributions would be depending greatly on the accuracy of wind directions, wind speeds, and atmospheric turbulence used in pollutant transport and diffusion models [10-11]. The three dimensional meso-scale model 'Atmospheric to Computational Fluid Dynamics (A2C flow/A2C t\&d)' where 't\&d' stands for transport and diffusion, which is updated version of HOTMAC/RAPTAD [12]. Different efficient modeling tools have been developed by focusing on types of pollutants, scale and location of the study area such as "Rapid Air" uses modern scientific method based on open source Python libraries for city scale dispersion model [21] which cannot produce the appropriate results for air dispersion in coastal area. Therefore $\mathrm{A} 2 \mathrm{C}$ flow/A2C t\&d is introduced in this study to overcome the limitation of AERMOD especially for air dispersion in a coastal region.

\section{Methods}

\subsection{Meteorology Monitoring}

Incheon metropolitan city located at the west coast $\left(37^{\circ} 29^{\prime} \mathrm{N}, 126^{\circ} 38^{\prime} \mathrm{E}\right)$ of Korean Peninsula has been rapidly growing compared to other area major power plants, airport and sea port have been in operation along the coastal line and nearby islands which subsequently affect the local atmospheric environment [16]. Complex geography, multiple land use pattern, etc., generate complex wind flow pattern around the Incheon coastal area. In addition, the significant differences in air temperature between land surface and sea water cause the visible variation in surface wind speed, wind direction, mixing height, etc. with diurnal and nocturnal time period, and season. Incheon frequently experiences sea/land breeze mostly during summer season when the sea breeze penetrates about $30 \mathrm{~km}$ to landward and the land breeze penetrates about $20 \mathrm{~km}$ to seaward [16-17]. For studying the coastal air flow and air dispersion, the study domain was designed as in Figure 1 where the location of the meteorological monitoring station and stack emission source are highlighted.

Surface meteorology data and upper air data were monitored for setting the initial and boundary condition during the modeling study. Automatic Weather Station (AWS) data such as wind speed, wind direction, air temperature, relative humidity and pressure, which were monitored and published from the department of meteorology of nearby station, are referred as surface meteorology data. The upper air data were monitored from the point at $37^{\circ} 30^{\prime} 26^{\prime \prime} \mathrm{N}$, $126^{\circ} 36^{\prime} 50^{\prime \prime}$ near to the stack emission source as shown in Figure 1. Upper air data such as wind speed, wind direction, absolute temperature, relative humidity and pressure were monitored using radio sonde at 3AM, 9AM, 3PM and 9PM for the mid of summer season. 

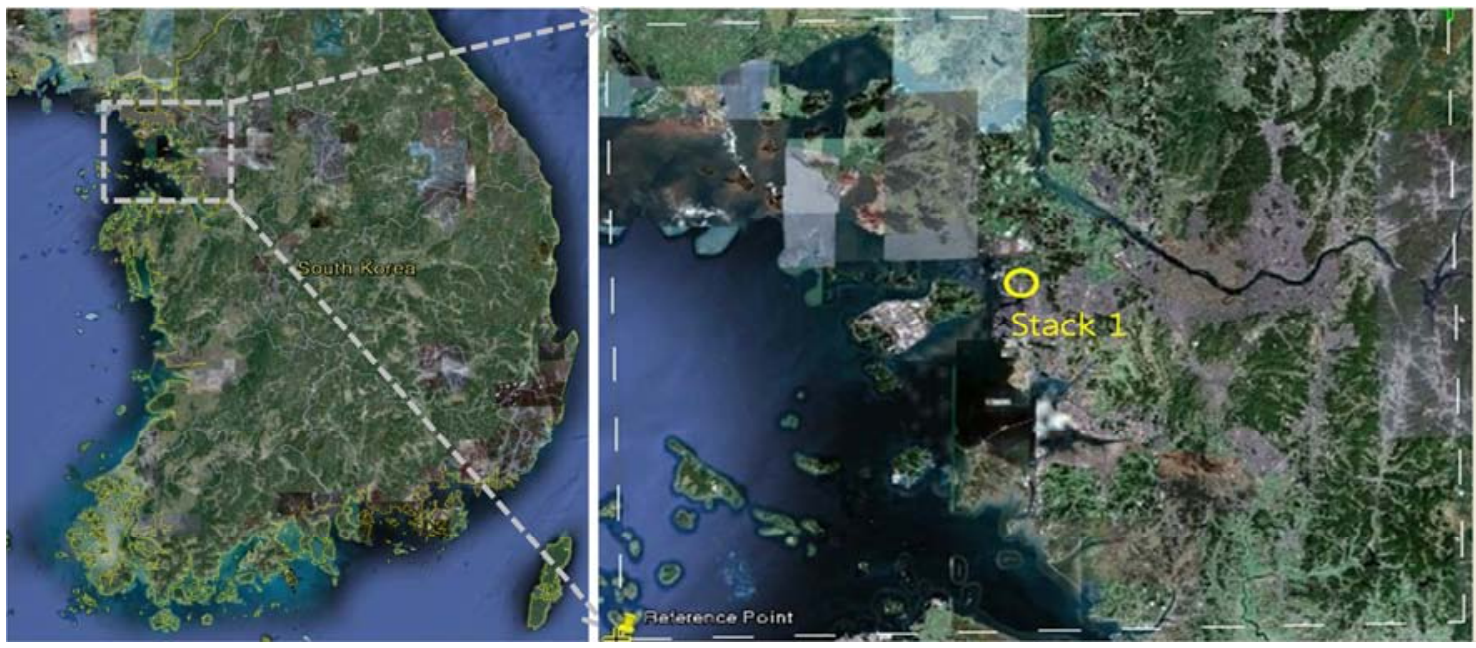

Figure 1. Left hand side image shows the South Korean peninsula and right hand side image shows the magnifying view of study site.

\subsection{Air Dispersion Modeling Method}

\subsubsection{Gaussian Plume Model (AERMOD)}

AERMOD modeling system consists of two pre-processors and the dispersion model. Terrain pre-processor (AERMAP) characterizes both the terrain and generates receptor grids for the dispersion model (AERMOD). AERMAP uses gridded terrain data for the modeling domain to calculate a representative terrain-influence height associated with each

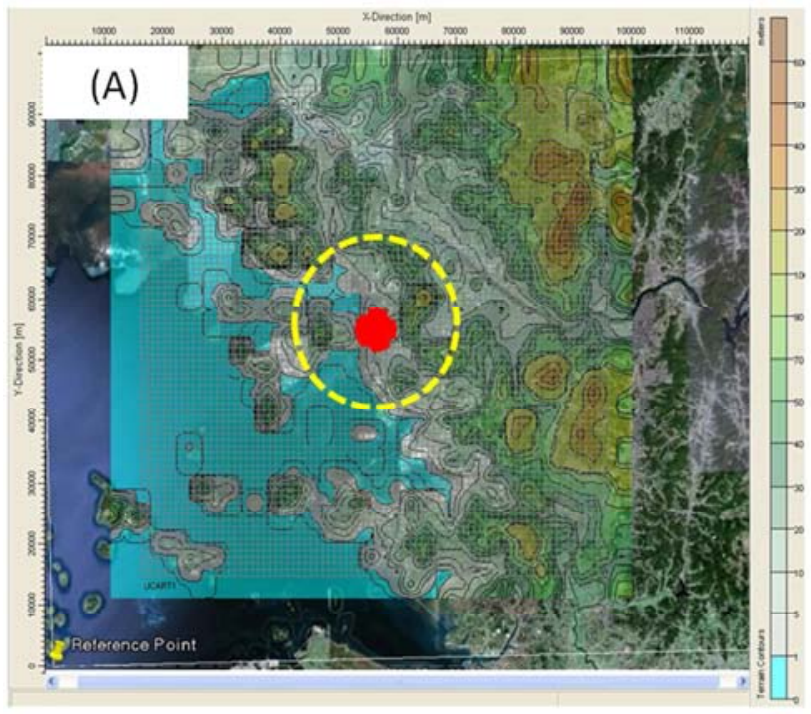

receptor location. The gridded data is supplied to AERMAP in the format of the Digital Elevation model (DEM) with a horizontal grid spacing of 30", i.e. GTOPO30 for the modeling domain. The geographic location of stack at the modeling is shown in Figure 2 (A) and (B). The stack height of $65 \mathrm{~m}$, the internal diameter of $5.5 \mathrm{~m}$, the pollutant emission velocity of $5 \mathrm{~m} / \mathrm{s}$, the exit temperature of $400 \mathrm{~K}$ and emission rate of $1 \mathrm{~g} / \mathrm{s}$ were established in this modeling case study.

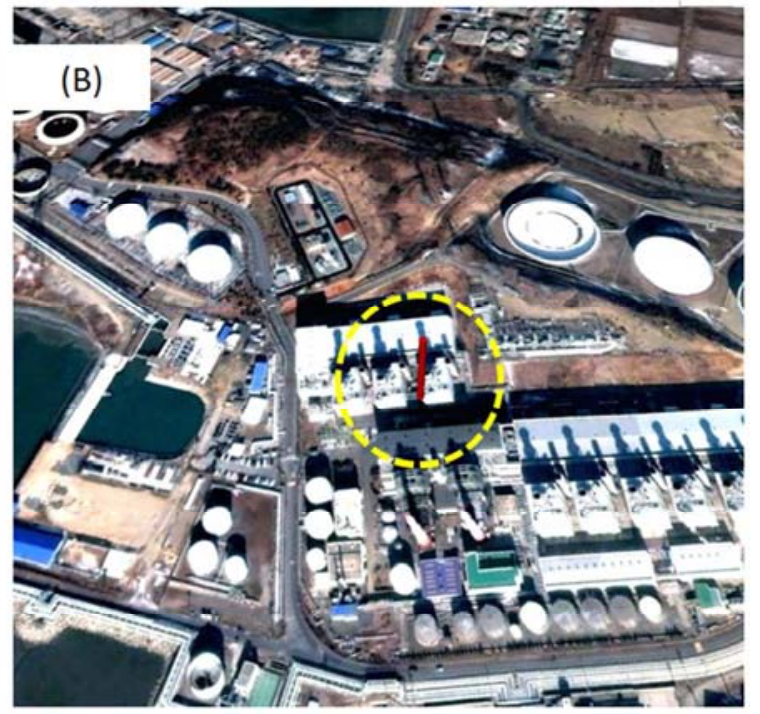

Figure 2. Geographic location of stack emission source at the modeling domain on the west coast of Korean Peninsula.

Meteorological preprocessor (AERMET) provides AERMOD the meteorological information to characterize the PBL. AERMET uses the meteorological data and surface characteristics to calculate boundary layer parameters (e.g. mixing height, friction velocity, etc.) for AERMOD. This data must be the representative of the meteorology in the modeling domain. We referred the meteorological data of dry bulb temperature, relative humidity, opaque cloud, station pressure, wind speed, wind direction to set the initial and boundary condition for the mid of July 2010 when sea/land breezes are frequently generated. Then the AERMOD modeling was accomplished to achieve the air dispersion characteristics in the study area.

\subsubsection{Lagrangian Puff Model (A2CFLOW/A2Ct\&d)}

USGS 30" resolution geographic data (about $800 \mathrm{~m}$ resolution at mid latitude) was used for extracting the geographic information for the modeling domain. The modeling domain lies between longitude $125.22 \mathrm{E}$, latitude $36.32 \mathrm{~N}$ to longitude $127.95 \mathrm{E}$, latitude $38.39 \mathrm{~N}$, which covers Incheon, Seoul and neighboring mountains and sea area as in Figure 1. The modeling period was selected in late July (Julian day 198 204) as same as AERMOD when the 
frequency of $\mathrm{S} / \mathrm{L}$ breeze was the maximum [16, 18]. Although we simulated for Julian day 198 204, the results are summarized for Julian day 200, the middle of modeling period, to avoid the effects of initial and boundary conditions. Initial conditions are summarized in Table 1, which are based on the monitoring data and references [16-19]. Initial wind speed, $0 \mathrm{~m} / \mathrm{s}$ was set by assuming the pure $\mathrm{S} / \mathrm{L}$ breeze case, i.e. no influence of external or synoptic wind and the inversion height of $700 \mathrm{~m}$ were set based on the monitored data as for the day time. There was no wind flow at the beginning of modeling period and the initial wind direction is insignificant. In addition, the nudging option set active for maintaining boundary conditions same as the initial values and HOTMAC (A2Cflow) computations become stable. Earth rotation option set active by considering the Coriolis Effect. The rests of the parameters such as turbulence variables, radiation variables, etc. were set as the default values (A2Cflow/A2Ct\&d (HOTMAC/RAPTAD) 9.1, User manual).

Puff emission source (SA0) was set at the coast line and the puff sampling sites SA1 SA6 were set at the land side and sea side by assuming the puffs transport to offshore by sea breeze and onshore by land breeze around the coastal area. Pokhrel et al. (2011) reported that the penetration length of sea breeze and land breeze are approximately $25 \mathrm{~km} \sim 30 \mathrm{~km}$ and $15 \mathrm{~km}$, respectively and the puffs sampling sites are set up to $30 \mathrm{~km}$ from the coast line as in Figure 3 (C). Sampling sites SA1, SA2 and SA3 are $10 \mathrm{~km}, 20 \mathrm{~km}$ and $30 \mathrm{~km}$, respectively far from the coast line and situated at the land side. Similarly sites SA4, SA5 and SA6 are $10 \mathrm{~km}, 20 \mathrm{~km}$ and $30 \mathrm{~km}$, respectively far from the coast line and situated at the sea side. Then the $\mathrm{A} 2 \mathrm{C}$ flow modeling was carried out for the meteorological modeling and the A2Ct\&d used the meteorological data produced by A2Cflowmodeling for study the puffs transport and dispersion study.

Table 1. Description of modeling criteria for A2C flow/A2C $t \& d$.

\begin{tabular}{lll}
\hline S.N. & Parameters & Conditions \\
\hline 1 & Model domain & $248 \mathrm{~km} \times 224 \mathrm{~km}$ \\
2 & Modelling period & Mid of July (Julian day 198 204) \\
3 & Potential temperature & $298 \mathrm{~K}$ \\
4 & Initial wind speed & $0 \mathrm{~m} / \mathrm{s}$ \\
5 & Initial wind direction & 0 degree \\
6 & Inversion height & $700 \mathrm{~m}$ \\
7 & Geographic data & USGS $30 "$ \\
8 & Stack height & $65 \mathrm{~m}$ \\
9 & Internal diameter & $5.5 \mathrm{~m}$ \\
10 & Exit velocity & $5 \mathrm{~m} / \mathrm{s}$ \\
11 & Exit temperature & $400 \mathrm{~K}$ \\
12 & Emission rate & $1 \mathrm{~g} / \mathrm{s}$ \\
\hline
\end{tabular}
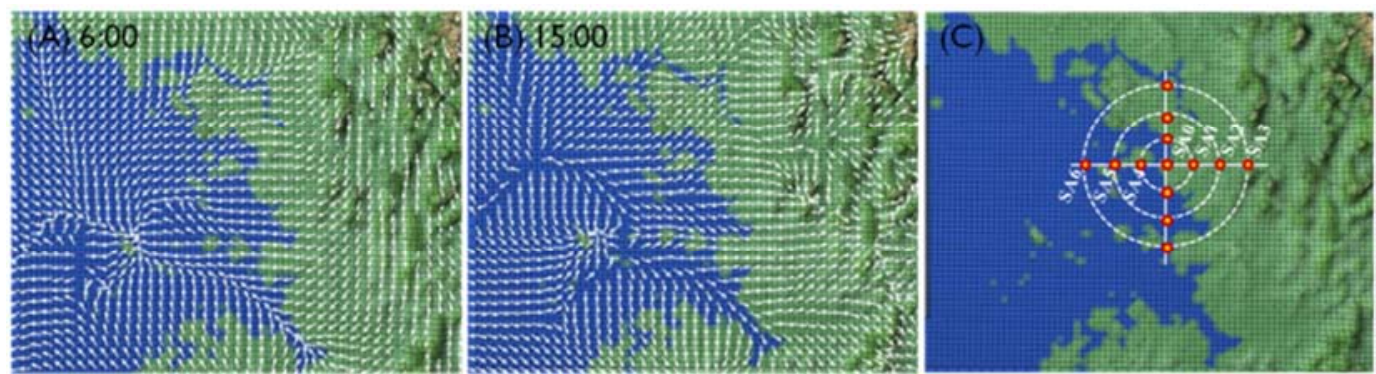

Figure 3. Wind flow vectors (A) at early morning 6AM when speed of the land breeze is the maximum, (B) at noon $3 P M$ when speed of the sea breeze is the maximum and $(C)$ the pollutant sampling spots in modeling domain.

\section{Results and Discussion}

The one hour average wind speed of calm to approximately $5.5 \mathrm{~m} / \mathrm{s}$ was observed at the monitoring site of Incheon area. The majority of wind blows from NNW, N, and NNE during the autumn and winter season. Similarly, the majority of the wind blows from SW and NNW during the spring and the majority of the wind blows from SW during summer season. The vertical wind profile shows that the inversion heights at night and daytime are approximately $300 \mathrm{~m}$ and $700 \mathrm{~m}$, respectively.

The maximum air temperature difference between the land surface and the sea surface was approximately $5^{\circ} \mathrm{C}$. The maximum sea water temperature at the surface during summer is approximately $27^{\circ} \mathrm{C}$ which is similar to surface water temperature of Lake Erie during summer. When the sea/land breeze index of 3.0 is applied for Incheon area, frequent sea breeze events are found in late spring to summer season. The case with the index values greater than 3.0 are reported as external wind in this study. Hence the modeling study is carried out for the mid of summer using modeling tool AERMOD and A2C flow/A2C t\&d.

The modeling domain and meteorological data were prepared using two preprocessor such as AERMAP and AERMET of AERMOD. The initial and boundary conditions are fixed by introducing the required meteorological data; however the AERMOD only uses average values for the modeling period. If the air flow patterns i.e. wind speed and direction is similar for whole day, the average value will be acceptable. Figure 4 (A) and (B) visualize the puffs dispersion phenomenon around the stack where Figure 4 (A) displays the 6 hours average puffs dispersion characteristics and Figure 4 (B) displays the 12 hours average puffs dispersion characteristics. Puffs transport and dispersion trend is similar whether 6 hours average or 12 hours average. AERMOD does not produce the data for the breeze flow therefore the air pollution dispersion produced by AERMOD is controlled by the average steady airflow data. 

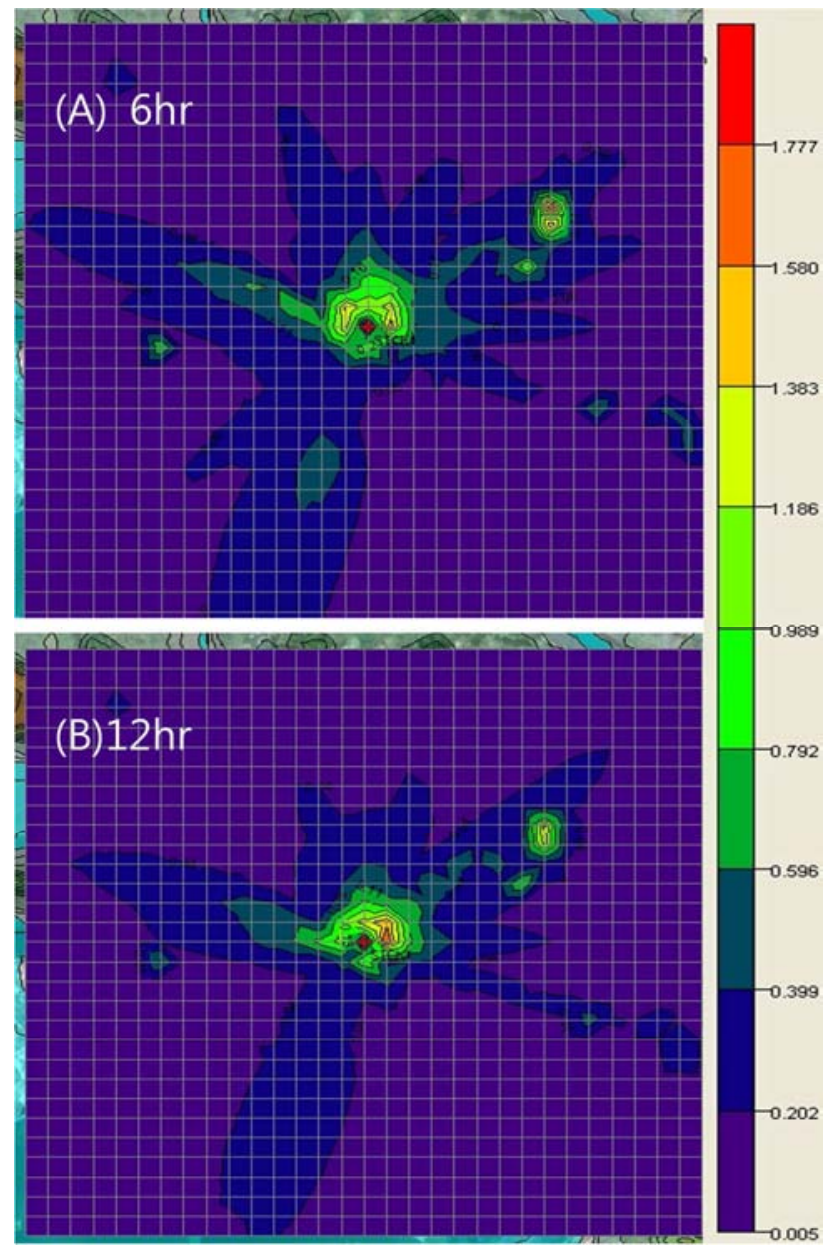

Figure 4. AERMOD visualize the transports and dispersions of puff around the coastal area (A) 6 hours average data and (B) 12 hours average concentration of puffs in $\mu \mathrm{g} / \mathrm{m}^{3}$.
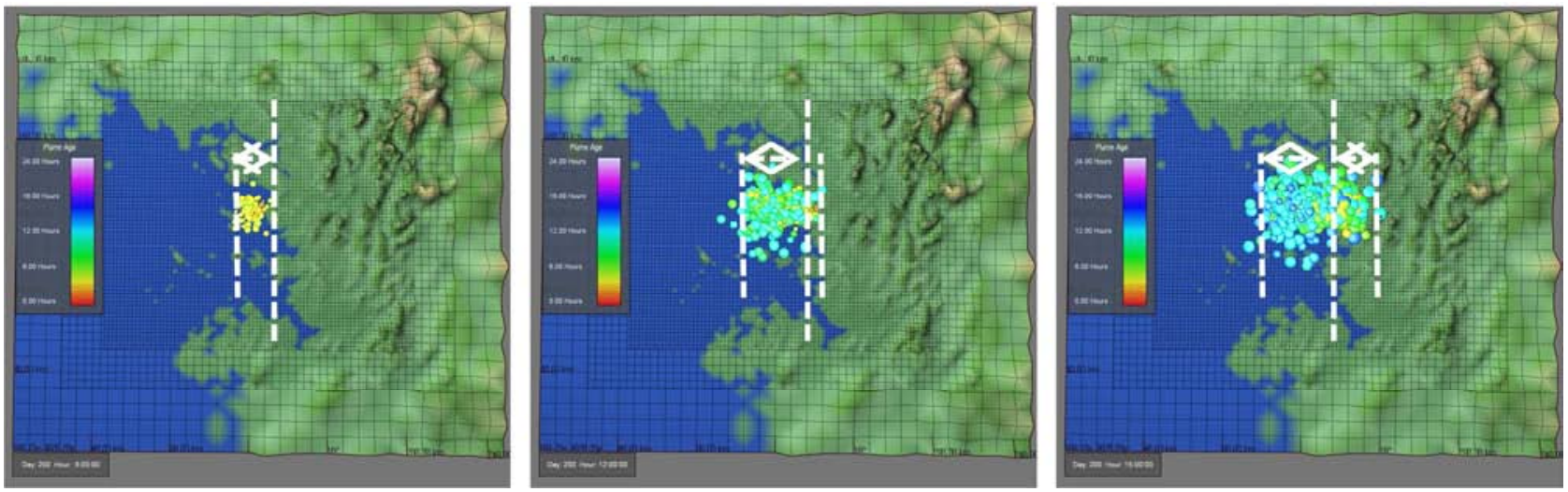

Figure 5. A2Cmodel visualize the transports and dispersions of puff by sea/land breeze around the coastal area at 6AM, 12PM and 3PM; strong land breeze is observed around $6 A M$ and the sea breeze is observed around $3 P M$ at the west coast of Incheon area.

Figure 5 demonstrates the results produced by A2Cflow/A2Ct\&d for the transport and dispersion of puffs from a stack source to the surrounding area. The puff which discharges from the stack is transported and dispersed around the stack source depending on the local meteorology condition. The land breeze is generated during late night to early morning when the puffs transport and disperse to seaward where the puffs travel approximately $15 \mathrm{kmfrom}$ the
A2C flow generates the meteorological information of surface and upper air based on the given initial and boundary condition data. Even the radiation energy is constant, the temperature differs significantly place to place due to the different land use pattern and specific heat capacities of land use objects. After the sunset, the land surface releases heat faster than water body, subsequently the land surface temperature becomes lower than the sea surface in late evening to early morning before sunrise [4]. In addition, the pressure above the sea surface becomes lower than the pressure above the land surface which causes the dynamic air flow from land to seaward (land breeze) and it gains its maximum speed just before the sunrise around 6AM as in Figure 3 (A). After the sunrise, the land surface heats faster than the water surface because of the lower specific heat capacity of the land than the sea water. Correspondingly, the potential temperature difference between the land and the sea surface reaches to the minimum which results the collapse of land breeze and reaches to transition stage around 9AM 10AM. When the temperature of the land surface reaches considerably higher than sea water, the air above the land surface rises up consequently the pressure above the land surface becomes lower than the pressure above the sea water surface. Then the air flows from the higher pressure side to the lower pressure, i.e. the sea breeze as in Figure 3 (B).The land surface temperature diminishes faster than the water surface temperature with the declination of the solar radiation energy and hence the sea breeze continuously diminishes and reaches to the transition period again around 9PM 10PM. Further detail has been reported in Pokhrel et al. [17]. 


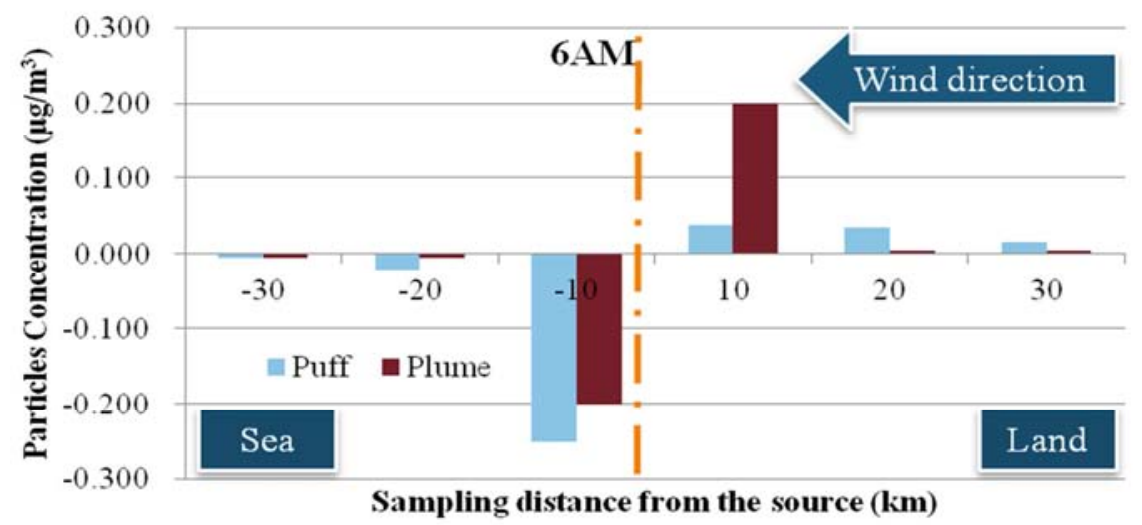

Figure 6. Concentration of puffs on sampling sites SA1 SA6 at 6AM.Puff and plume represent the A2C and AERMOD, respectively.

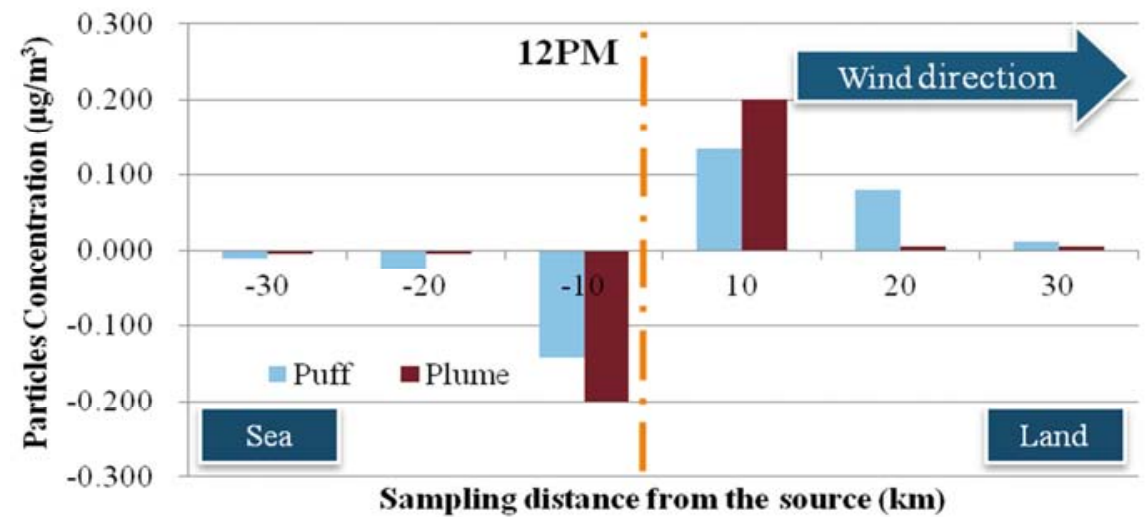

Figure 7. Concentration of puffs on sampling sites SA1 SA6 at 12PM. Puff and plume represent the A2C and AERMOD, respectively.

Figures 6 and 7 demonstrate the concentration of puffs during different time period at sampling points SA1 SA6. $\mathrm{X}$ axis represents the distance of sampling point from the coast line where the negative sign denotes the sampling points are at sea side and the positive sign denotes the sampling points are at land side. Similarly, the negative concentration means the concentration at the sea side. Figure 6 displays the concentration of puffs at different sampling sites at early morning 6AM when the land breeze is strong. AERMOD produces the similar puff concentration either onshore site or offshore sites but A2C t\&d produces approximately 5 times more puffs concentration at site SA4 than SA1. It determines that the deposition of puff is more at the sea surface during land breeze period. Figure 7 presents the concentration of puffs at sampling sites SA1 SA6 at $12 \mathrm{PM}$ when the sea breeze generates and transports the puffs towards the land side from the sources. There is no significant difference in puff concentration results produced by AERMOD either land breeze period or sea breeze. On the other hand the puffs concentration gradually reduces at the sea side and increases at the land side based on the concentration results produced by A2Cmodel. Finally, it is concluded that the Lagrangian based model is more reliable to study the breeze and air pollution transport \& dispersion around the coastal region than steady state plume model.

\section{Conclusion}

The meteorological data for both the surface and the upper air were prepared from the direct field monitoring and references. The AWS data confirmed that the majority of wind blows from NNW, N, \& NNE during the autumn and winter season, SW \& NNW during the spring and SW during summer season. The vertical wind profile results show that the height of the breeze approximately $300 \mathrm{~m}$ was observed at night time at $3 \mathrm{AM}$ and $700 \mathrm{~m}$ at day time $3 \mathrm{PM}$.

The modeling results shows that the Gaussian based model does not properly summarize the sea/land breeze event for the study domain and it only considers the average wind speed and direction data for air dispersion model. On the other hand, the Lagrangian based model produces the meteorological modeling results based on the initial and boundary condition data. The sea breeze penetrates to land side during late morning to late evening and the land breeze penetrates to sea side from mid night to early morning. The penetration length of sea breeze and land breeze were approximately $25 \mathrm{~km} \sim 30 \mathrm{~km}$ and $15 \mathrm{~km}$, respectively which significantly controls the transport and dispersion of puff from the sources.

The simulation based on the Gaussian theory (AERMOD) is comparatively less time consuming for processing and easy 
to run but it does not accept the assumption that the coastal air pollution dispersion by sea/land breeze. Pollutants, which were emitted from the source, transported and dispersed around the generation sources, and the pattern was similar with the average wind flow direction. Therefore there was no significant difference in pollutants dispersion and deposition pattern whether there was land breeze or sea breeze. On the other hand, the results produced by A2Cflow/A2Ct\&dmodels reveal that the puffs transport, dispersion and deposition around the coast area followed the sea/land breeze pattern. The comparative analysis of the pollutants deposition quantity estimated by the steady state Gaussian plume model and the Lagrangian model reveals that the Gaussian approach underestimates the pollution concentration at the onshore site during day time and overestimates during late night to early morning. Hence the Lagrangian based model is more reliable for evaluating the pollutants dispersion and deposition around the unsteady air flow region.

\section{Acknowledgements}

This research was supported by the Incheon National University Research Grant in 2015. Authors are thankful to AirGroup, Incheon National University for helping the data management and reviewing the manuscript. Authors would like to acknowledge the editor and the anonymous reviewers for their constructive suggestions and valuable comments.

\section{References}

[1] Seangkiatiyuth, K., Surapipith, V., Tantrakarnapa, K., Lothongkum, A.W. (2011). Application of the AERMOD modeling system for environmental impact assessment of NO2 emissions from a cement complex. J. of Environ. Sci. 23, 6, 931-940.

[2] Arya, S. P. (1999). Air Pollution meteorology and Dispersion. Oxford University Press, pp.69-104, 269-286.

[3] Srinivas, C.V., Venkatesan, R., Singh, A.B. (2007). Sensitivity of meso-scale simulations of land-sea breeze to boundary layer turbulence parameterization. Atmos. Environ. 41, 25342548 .

[4] Hsu, S.A. (1988). Coastal meteorology. Academic press, Inc. (London) LTD., pp. 141-179.

[5] Kim, D., William, R.S. (2007). An online coupled meteorological and air quality modeling study of the effect of complex terrain on the regional transport and transformation of air pollutants over the Western United States. Atmos. Environ. 41, 2319-2334.

[6] Karim, B., Mansour, B.F., Elouragini, S. (2007). Impact of a sea breeze event on air pollution at the Eastern Tunisian Coast. Atmos. Res. 86, 162-172.
[7] Fan, S., Wang, B., Tesche, M., Engelmann, R., Althausen, A., Liu, J., Zhu, W., Fan, Q., Lim., Ta, N., Song, L., Leong, K. (2008). Meteorological condition and structures of atmospheric boundary layer in October 2004 over Pearl River Delta area. Atmos. Environ. 42, 6147-6186.

[8] Peilke, R.A., Pearce, R.P. (1994). Mesoscale modeling of the atmosphere. Am. meteorol. Soc., 25, Boston, MA.

[9] Yamada, T., Bunker, S. (1988). Development of a nested grid, second moment turbulence closure model and application to the 1982 ASCOT Brush Creek data simulation. Journal of Applied meteorology and Climatology 27, 562-578.

[10] Yamada, T., Kao, J.C.Y., Bunker, S. (1989). Airflow and air quality simulations over the western mountainous region with a four dimensional data assimilation technique. Atmos. Environ. 23, 539-554.

[11] Yamada, T. (1999). A numerical simulation of urbanization on the local climate. J. Wind Eng. Ind, Aerodyn. 81, 1-19.

[12] Yamada, T. (2004). Merging CFD and atmospheric modeling capabilities to simulate airflows and dispersion in urban areas. CFD J. 13(2):47, 329-341.

[13] Schutze, M., Stratmann, F. (2008). Numerical simulation of cloud droplet formation in a tank. Comput. Geosci. 34, 10341043 .

[14] Pace, C.J. (2000). DTRA urban dispersion modeling support for special security events. In: Proceedings of the $11^{\text {th }}$ Joint Conference on the Application of Air Pollution meteorology with A\&WMA, 9-13 January, Long Beach, CA, Am. meteorol. Soc., Boston, $\mathrm{mA}$.

[15] EPA (2004). AERMOD: Description of model formulation. United States Environmental Protection Agency, 8-14.

[16] Jeong, J., Lee, I.H., Lee, H. (2008). Estimation of the effective region of Sea/Land breeze in west coast using numerical modeling. J. KOSAE 24, 2, 259-270.

[17] Pokhrel, R., Lee, H. (2011). Estimation of the effective zone of sea/land breeze in a coastal area. APR 2, 106-115.

[18] Lee, I., Lee, H. (2004). Analysis of meteorological characteristics of Sea/Land breeze in western coastal region. J. Korean Society of Urban Environ. 4, 1, 63-71.

[19] Annual climatological report, Korean meteorological administration (2010). Seoul Korea.

[20] Leelossy, A., Molnar Jr, F., Izsak, F., Havast, A., Lagzi, I., Meszaros, R. (2014) Dispersion modeling of air pollutants in the atmosphere: a review. Cent. Eur. J. Geosci. 6(3), 257-278.

[21] Masey, N., Hamilton, S., Beverland, I.J. (2018) Development and evaluation of the Rapid Air dispersion model, including the use of geospatial surrogates to represent street canyon effects. Environmental modeling \& Software, 108, 253-263. 